\title{
Optical measurement system applied to continuous displacement monitoring of long-span suspension bridges
}

L. Lages Martins*a ${ }^{\mathrm{a}}$ J. M. Rebordão ${ }^{\mathrm{b}}$, A. Silva Ribeiro ${ }^{\mathrm{a}}$

${ }^{a}$ National Laboratory for Civil Engineering, Avenida do Brasil 101, 1700-066 Lisbon, Portugal;

${ }^{b}$ Laboratory of Optics, Lasers and Systems, Physics Department, Faculty of Sciences, University of Lisbon, Campo Grande, 1749-016 Lisbon, Portugal

\section{ABSTRACT}

This paper provides a general description of main issues related to the design of an optical measurement system applied to continuous displacement monitoring of long-span suspension bridges. The proposed system's architecture is presented and its main components - camera and active targets - are described in terms of geometrical and radiometric characteristics required for long distance measurement of the tridimensional displacement of the stiffness girder in the middle section of the bridge's central span. The intrinsic and extrinsic camera parameterization processes, which support the adopted measurement approach, are explained in a specific section. Since the designed measurement system is intended to perform continuous displacement monitoring in long distance observation framework, particular attention is given to environmental effects, namely, refraction, turbulence and sensor saturation phenomena, which can influence the displacement measurement accuracy. Finally, a measurement uncertainty method is discussed in order to provide a suitable solution for the determination of the accuracy related to the proposed measurement approach.

Keywords: displacement optical measurement, suspension bridge structural monitoring 